\title{
Creativity among Geomatical Engineering Students
}

\author{
Lim Keng Keh ${ }^{1}$, Zaleha Ismail ${ }^{1} \&$ Yudariah Mohammad Yusof ${ }^{2}$ \\ ${ }^{1}$ Mathematics Education, Universiti Teknologi Malaysia, Johor Bahru, Malaysia \\ ${ }^{2}$ Mathematical Science, Universiti Teknologi Malaysia, Johor Bahru, Malaysia \\ Correspondence: Lim Keng Keh, Mathematics Education, Universiti Teknologi Malaysia, Johor Bahru, Malaysia. \\ E-mail:kklim6@live.utm.my
}

Received: October 9, 2016

Accepted: November 13, 2016

Online Published: March 30, 2017

doi:10.5539/ies.v10n4p43

URL: https://doi.org/10.5539/ies.v10n4p43

\begin{abstract}
This research aims to find out the creativity among the geomatical engineering students. 96 geomatical engineering students participated in the research. They were divided into 24 groups of 4 students. Each group were asked to solve a real world problem collaboratively with their creative thinking. Their works were collected and then analysed as to compare their creativity based on their fluency, flexibility and originality. The results showed that the students were able to use their creativity and came out with many different methods to solve the problem. The results also showed that the components of creativity namely fluency, flexibility and originality can be used to assess the creativity among the groups of students.
\end{abstract}

Keywords: creativity, fluency, flexibility, originality, engineering students

\section{Introduction}

Liu (2004) stated that most companies and industries need engineers who can solve problem creatively and think outside the box. Therefore, engineering students have to strive for innovative and highest level of creativity in order to survive in their future real world, as most employers nowadays are looking only for engineering graduates who not only can think critically but also can think creatively (Wilbur, 2013). Wilbur also mentioned that engineering students have to learn how to face real world problem and not every real world problem can be solved as easily as their mathematical problems on their homework worksheets, Ahern et al. (2012) also claimed that most employers are looking for engineering graduates who can think critically; however, universities do not provide these type of graduates who can meet the requirements of the employers. Therefore, there is an increasing pressure for universities to develop their students with generic skills such as critical and creative thinking, problem solving, communication, interpersonal, logical and information management skills (Bath et al., 2004).

According to Hilal, Husin, and Zayed (2013), there are certain barriers to creativity among the engineering undergraduates in Malaysia such as barriers related to self-concept, barriers related to compliance need, barriers related to abstract ability, barriers related to systematic analysis, barriers related to task achievement and barriers related to environmental circumstances. They carried out a research to find out that the barriers to creativity among 459 undergraduates in several public universities in Malaysia. The findings showed that barriers related to task achievement is the most difficult barriers to deal with by the undergraduates, followed by barriers related to self-concept and barriers related to environmental circumstances.

They claimed that the use of various techniques such as reinforcement, instruction, modelling, self-management training, component-skills training and problem-solving training can help students to spur their creativity and also overcome the barriers to creativity Tong (2003) stated that project management skills can be integrated in the engineering curriculum in order to help the engineering undergraduates to transfer their hard and soft skills from their classroom environment to their future real world. They told us that most engineering schools still provide the students with little non-technical skills.

Engineering students nowadays face the problem of applying whatever they have learnt in the university to their future real world. According to Wilbur (2013), we have to understand the reasons behind this growing problem. One of the reasons is due to the design of curriculum. The lack of creative projects in university curricula encourages students to use their abilities to solve their problem creatively. Students also feel uncomfortably to solve an open-ended problem because they may afraid they can't come up with a correct solution. Another 
reason is the difficulty to evaluate the level of creativity among the students. Wilbur (2013) also mentioned that the lack of definition of level of creativity also inhibit professors to judge their students based on level of creativity However, the infusion of open-mindedness and creativity in engineering curricula can help engineering students to develop their creative thinking (Wilbur, 2013). According to Genco (2012), students can learn how to use their creativity and generate new ideas in the school by exploring themselves to various techniques. Therefore, university is still considered the best place for students to experiment with their creativity. Students can use their class time to explore and discover their creative thinking when they working with their projects.

According to Felder (1987), there are certain ways to stimulate creativity in engineering students. First, by exploring the students to open-ended problems so that they need to learn how to gather enough information to solve the problem. By using brainstorming exercise, students can generate many possible ways to solve a problem in a small group activity. Small group discussion can provide good environment for students to generate many new ideas and thus develop their creative problem solving skills. Making up a problem is also another way to help students to come up with their creative ideas. Questions which are poorly defined, divergent, open-ended and require students to look for enough information to define and understand the problem. Questions which require ideational fluency (quantity of solutions), flexibility (variety of solutions) and originality (unique solution) also can help students to stimulate their creativity (Felder, 1987). Felder (1987) also mentioned that the methods used to stimulate students' creativity should not take too much of the teaching and learning time.

\section{Creativity}

There are many definitions regarding creativity. Creativity can be defined as generation of new ideas (Newell \& Shaw, 1972). Some defined creativity as generation of creative solution by integrating existing knowledge in many different ways. Others suggest creativity must has value either in new solution or recombined with other ideas (Higgns, 1999). There are many definitions regarding creativity.

Haylock (1987) defined creativity as the ability to associate the unrelated ideas with applications. He believed that creative ideas can be generated by overcoming the fixation barriers. Krutetskill (1976) characterized creativity with problem finding, originality and invention. Runco (1993a) stated that creativity involves divergent and convergent thinking, problem finding and problem solving. Runco (1993) also described that "mathematical creativity is multifaceted and requires divergent and convergent thinking, problem finding and problem solving, self-expression, intrinsic motivation, a questioning attitude, and self-confidence." Students must involve themselves in divergent thinking and problem solving in order to have better skills in mathematical creativity. One of the skills is known as creative problem solving skill (Runco, 1993). Boden (2004) mentioned that combining familiar ideas in unfamiliar ways is known as creativity. According to Boden, there are three types of creativity to generate new ideas. The first type is combinational creativity which can use familiar ideas to generate new idea. The second type is the exploratory creativity which can generate new idea by exploring structured concepts. The third is the transformational creativity which transform some dimensions of the structures to come out with new structure. Therefore, the process of exploring and transforming a conceptual space can be used to generate creativity.

All the definitions are actually can be combined into three main categories. These are known as creative person, products and processes. Creative person is based on the intellectual, motivation, personality and other characteristics. The creative products are outcome or result based on its usefulness and novelty. The creative processes are focused on the cognitive processes to come out with creative products. Creativity can be described with four overlapping themes such as the characteristics of creative people, the outcome, product of creativity and the context of creativity (Isaksen, Dorval, \& Treffinger, 2011). Isaken (1989) represented these four themes and showed their interactions in order to get a whole picture of creativity.

The first theme is used to understand the characteristics of creative people. In order to find out the characteristics of creative people, we have to look into the cognitive and affective characteristic of them. These characteristics are actually dynamic, changeable, they are not fixed and can be modified and enhanced by nurturing (Isaksen, Dorval, \& Treffinger, 2011). A great number of research had been used to identify the characteristics of highly creative people and the results showed that creativity existed not only in geniuses but also in normal people such as us at all levels to certain degrees (Isaksen, Dorval, \& Treffinger, 2011). The characteristics of creative people are known as openness, imagination, curiosity, playfulness, originality, flexibility, fluency, complexity, tolerance of ambiguity, high energy, elaboration, independence, risk-taking and capacity to make order from chaos (Isaksen, Dorval, \& Treffinger, 2011).

The second theme is known as process or operation performed by creative people (Isaksen, Dorval, \& Treffinger, 2011). Walls (1926) developed the creative process based on famous artists and scientists. He suggested that four 
stages of creative thinking in creative process such as preparation, incubation, illumination and verification. Osborn $(1942,1953)$ built on the work of Wallas and continued on this research and developed strategies to be applied in groups. The research to understand creative process still continues even until today.

Creative products or outcomes is the next theme and they can be found in many field of study and not only in arts and sciences (Isaksen, Dorval \& Treffinger, 2011). They can be tangible and concrete product such as invention and tool or intangible and soft product such as design and methodology. Assessment of creativity in terms of creative products or creative outcomes had been developed by Besemer and her colleagues (Besemer, 1997; Besemer \& O’Quin, 1987, 1993, 1999; Besemer \& Treffinger, 1981). Creative products can be evaluated based on three dimensions as shown in the following diagram Figure 2.2 (Isaksen, Dorval, \& Treffinger, 2011). The first dimension is novelty which shows the originality and newness of the products. The second dimension is resolution which shows the effectiveness of using the products to solve a problem. The third dimension is style which shows how attractive and elegant the product is. It is the extension or elaboration of the product and extends beyond the basic requirement of the product (Isaksen, Dorval, \& Treffinger, 2011).

Creative context is the last theme and it enables us to understand the place, climate, culture or environment where creativity can flourish (Isaksen, Dorval, \& Treffinger, 2011). There are factors to stimulate the climate for creativity such as freedom of trying new methods; respect, accept and support unusual and creative ideas of others; accept challenges to solve problem in new different ways; provide right amount of time to accomplish a task; allow people to work either alone or in a group to exchange ideas; encourage people to learn from their mistakes; tolerate people's diversity and different points of view; create some degree of flexibility in organizing and planning; willing to take risk and not afraid to make mistakes (Isaksen, Dorval, \& Treffinger, 2011). A climate in which creativity occurs can promote creative behavior (Isaksen, Dorval, \& Treffinger, 2011). Alan Alda once told us that we have to be brave enough to leave our comfort zones and venture to a place where no one has ever gone before as to discover for ourselves your own creativity. This creative place is our wilderness of our intuition and we can't get there by bus but only by our hard work, curiosity and willing to take risk. In his famous quote,"'Be brave enough to live life creatively. The creative is the place where no one else has ever been. You have to leave the city of your comfort and go into the wilderness of your intuition. You can't get there by bus, only by hard work and risk and by not quite knowing what you're doing. What you'll discover will be wonderful. What you'll discover will be yourself'" (Chang, 2006).

Guilford started his research by developing intelligence tests to select pilots during World War II (Barlow, 2000). He developed a model to guide his research of finding the creativity among the people. In his book "The Nature of Human Intelligence", Guilford (1967) proposed a model of intelligence and represented it with a cube of 150 factors. He also found that a person can be high in certain ability and low in others, he wrote a book in the year of 1977, "Way beyond the IQ" to show that a person's creativity can't be determined by his or her IQ.

In his new model, he divided human abilities into categories of three different dimensions such as contents, products and operations (Barlow, 2000). There are five kinds of operations such as evaluation (ability to make judgment based on information), convergent production (ability to look for single solution for a problem), divergent production (ability to look for many solutions for a problem), memory (ability to store or retrieve information) and cognition (ability to perceive information collected); six kinds of products such as units (the ability to perceive a single item), classes (ability to organize units into a group), relations (ability to sense the relationship of a pair of units), systems (ability to sense the relations of more than two units), transformation (ability to understand changes in information) and implications(ability to make inference of information); fix kinds of contents such as visual (ability to perceive information from seeing), auditory (ability to perceive information from hearing), symbolic (ability to perceive information in symbols or signs), semantic (ability to perceive information in words or sentences) and behavioral (ability to perceive information in behavior) (Barlow, 2000).

\section{Methodology}

This was an exploratory research carried out in a local university as to find out the creativity among the geomatical engineering undergraduates. 96 undergraduates were divided into 24 groups and worked collaboratively in the process of problem solving. The students used their creativity and came out with many different methods to solve the problem. Their works were later on collected and analysed as to compare the creativity among the groups.

The students were asked to propose a method to find out the length of the bridge across the river. From the literature review, three components were used to measure the students' creativity namely fluency, flexibility and originality. Fluency was used to measure the students' ability to generate as many methods as possible to find out 
the solution for the problem. Flexibility was the next elements as to find out the students' ability to come out with various types of methods towards the problem. The last elements of originality were used to measure the students' ability to come out with unique and unusual methods to solve the problem. 24 groups of students were compared based on these three elements of creativity. One point was given to any group for each method suggested by the group. One point was also given to the group for different types of methods proposed. From the document analysis, there were altogether three different categories of methods to solve the problem proposed by the group, namely using photogrammetry and scale on map, using triangulation, coordinates and GPS, using hydro graphic survey and time of flight by boat, using LIDAR. Originality was measured by using a scale of 0 to 5 based on the frequency of the methods suggested by the groups in related to the overall total number of groups. Scale of 5 was given to any group with the lowest frequency of the methods suggested and scale of 0 was given to the group with the highest frequency of the methods. The following table showed the scales based on the total responses from the groups with respect to the total number of groups for each method suggested by the group.

\section{Findings}

Some groups of students suggested to use scale on map as a way to find out the real distance across the river. Another groups of students proposed to use aerial photographs taken from drone or UAV, an acronym for Unmanned Aerial Vehicle in order to calculate the distance across. Others suggested using triangulation as a method to triangulate the three points taken either from GPS or total stations. Some groups even used hydro graphic survey as a mean to find out distance across the river indirectly. Only a few groups came out with unique ways of solving the problem by proposing to use LIDAR which stands for Light Detection and Ranging to measure the distance. The different methods used were categorized into three categories. This was based on the themes of using ratio, points and reflection. Photogrammetry and scale on map were grouped together as both of them was using ratio to calculate the distance. Coordinates, triangulation and GPS were also categorized as the same group as they were using points to measure the distance across. The last category of hydrographic survey and LIDAR was using reflection of sound and light as medium to find out the distance. The following Table 1 showed the different methods suggested by each groups.

Table 1. Methods suggested by the groups

\begin{tabular}{|c|c|c|c|c|c|c|c|}
\hline \multirow[b]{3}{*}{ Group } & \multicolumn{2}{|c|}{ Category 1} & \multicolumn{3}{|c|}{ Category 2} & \multicolumn{2}{|c|}{ Category 3} \\
\hline & Method 1 & Method 2 & Method 3 & Method 4 & Method 5 & Method 6 & Method 7 \\
\hline & $\begin{array}{c}\text { Photogrammetr } \\
\text { y and aerial } \\
\text { photo }\end{array}$ & Scale on map & $\begin{array}{l}\text { Coordinates } \\
\text { and distance } \\
\text { formula }\end{array}$ & $\begin{array}{l}\text { Triangulation, } \\
\text { triangles and } \\
\text { traverse }\end{array}$ & GPS & $\begin{array}{l}\text { Hydrography, } \\
\text { time of flight } \\
\text { and soundings }\end{array}$ & LIDAR \\
\hline Group 1 & & & $\mathrm{x}$ & & $\mathrm{x}$ & $\mathrm{x}$ & $\mathrm{x}$ \\
\hline Group 2 & $\mathrm{x}$ & $\mathrm{x}$ & $\mathrm{x}$ & & $\mathrm{x}$ & $\mathrm{x}$ & \\
\hline Group 3 & & & $\mathrm{x}$ & $\mathrm{x}$ & $\mathrm{x}$ & & \\
\hline Group 4 & $\mathrm{x}$ & & & $\mathrm{x}$ & $\mathrm{x}$ & $\mathrm{x}$ & \\
\hline Group 5 & & & $\mathrm{x}$ & $\mathrm{x}$ & $\mathrm{x}$ & & \\
\hline Group 6 & $\mathrm{x}$ & $\mathrm{x}$ & & $\mathrm{x}$ & $\mathrm{x}$ & & \\
\hline Group 7 & $\mathrm{x}$ & $\mathrm{x}$ & & $\mathrm{x}$ & $\mathrm{x}$ & $\mathrm{x}$ & \\
\hline Group 8 & $\mathrm{x}$ & & $\mathrm{x}$ & & $\mathrm{x}$ & $\mathrm{x}$ & \\
\hline Group 9 & & $\mathrm{x}$ & $\mathrm{x}$ & $\mathrm{x}$ & & $\mathrm{x}$ & \\
\hline Group 10 & $\mathrm{x}$ & & $\mathrm{x}$ & $\mathrm{x}$ & $\mathrm{x}$ & $\mathrm{x}$ & \\
\hline Group 11 & $\mathrm{x}$ & & $\mathrm{x}$ & $\mathrm{x}$ & & & $\mathrm{x}$ \\
\hline Group 12 & & & $\mathrm{x}$ & $\mathrm{x}$ & $\mathrm{x}$ & & \\
\hline Group 13 & $\mathrm{x}$ & $\mathrm{x}$ & $\mathrm{x}$ & $\mathrm{x}$ & & $\mathrm{x}$ & \\
\hline Group 14 & & $\mathrm{x}$ & $\mathrm{x}$ & & & & \\
\hline Group 15 & & & & & $\mathrm{x}$ & $\mathrm{x}$ & $\mathrm{x}$ \\
\hline Group 16 & & $\mathrm{x}$ & $\mathrm{x}$ & $\mathrm{x}$ & & & \\
\hline Group 17 & & & & & & $\mathrm{x}$ & \\
\hline Group 18 & $\mathrm{x}$ & & & $\mathrm{x}$ & $\mathrm{x}$ & $\mathrm{x}$ & \\
\hline Group 19 & $\mathrm{x}$ & & $\mathrm{x}$ & $\mathrm{x}$ & $\mathrm{x}$ & $\mathrm{x}$ & \\
\hline
\end{tabular}




\begin{tabular}{lllll}
\hline Group 20 & & & $\mathrm{x}$ & $\mathrm{x}$ \\
Group 21 & $\mathrm{x}$ & $\mathrm{x}$ & $\mathrm{x}$ & $\mathrm{x}$ \\
Group 22 & $\mathrm{x}$ & $\mathrm{x}$ & $\mathrm{x}$ & $\mathrm{x}$ \\
Group 23 & & $\mathrm{x}$ & $\mathrm{x}$ & $\mathrm{x}$ \\
Group 24 & $\mathrm{x}$ & $\mathrm{x}$ & & $\mathrm{x}$ \\
\hline
\end{tabular}

The result in the following Table 2 showed that method 7 was the unique way of solving the problem as compared to other methods used among the groups. The common method proposed by the groups was using GPS which stands for Global Positioning System.

Table 2. Comparison among the groups based on a scale

\begin{tabular}{cccccccc}
\hline & \multicolumn{2}{c}{ Category 1 } & \multicolumn{3}{c}{ Category 2 } & \multicolumn{2}{c}{ Category 3 } \\
\cline { 2 - 8 } & \multicolumn{1}{c}{ Method 1 } & Method 2 & Method 3 & Method 4 & Method 5 & Method 6 & Method 7 \\
\cline { 2 - 8 } & $\begin{array}{c}\text { Photogrammet } \\
\text { ry and aerial } \\
\text { photo }\end{array}$ & Scale on map & $\begin{array}{c}\text { Coordinates } \\
\text { and distance } \\
\text { formula }\end{array}$ & $\begin{array}{c}\text { Triangulation, } \\
\text { triangles and } \\
\text { traverse }\end{array}$ & GPS & $\begin{array}{c}\text { Hydrography, } \\
\text { time of flight } \\
\text { and soundings }\end{array}$ & LIDAR \\
\hline $\begin{array}{c}\text { Total number of } \\
\text { response }\end{array}$ & 13 & 9 & 16 & 16 & 17 & 12 & 3 \\
$\begin{array}{c}\text { Percentage } \\
\text { Scale }\end{array}$ & $\begin{array}{c}54.17 \% \\
2\end{array}$ & $37.50 \%$ & $66.67 \%$ & $\begin{array}{c}66.67 \% \\
1\end{array}$ & $10.83 \%$ & $50.00 \%$ & $12.50 \%$ \\
\hline
\end{tabular}

The final result in the Table 3 showed the total points obtained by each group after adding their points of fluency, flexibility and originality. The result also showed that group 17 was the best performance group among them.

Table 3. Fluency, flexibility and originality among the groups

\begin{tabular}{|c|c|c|c|c|}
\hline & Fluency & Flexibility & Originality & Total \\
\hline Group 1 & 4 & 2 & 9 & 15 \\
\hline Group 2 & 5 & 3 & 10 & 18 \\
\hline Group 3 & 3 & 1 & 1 & 5 \\
\hline Group 4 & 4 & 3 & 5 & 12 \\
\hline Group 5 & 3 & 1 & 1 & 5 \\
\hline Group 6 & 4 & 2 & 6 & 12 \\
\hline Group 7 & 5 & 3 & 9 & 17 \\
\hline Group 8 & 4 & 3 & 6 & 13 \\
\hline Group 9 & 4 & 2 & 8 & 14 \\
\hline Group 10 & 5 & 3 & 6 & 14 \\
\hline Group 11 & 4 & 3 & 8 & 15 \\
\hline Group 12 & 3 & 1 & 1 & 5 \\
\hline Group 13 & 5 & 3 & 10 & 18 \\
\hline Group 14 & 2 & 1 & 5 & 8 \\
\hline Group 15 & 3 & 2 & 8 & 13 \\
\hline Group 16 & 3 & 1 & 5 & 9 \\
\hline Group 17 & 1 & 1 & 3 & 5 \\
\hline Group 18 & 4 & 3 & 5 & 12 \\
\hline Group 19 & 5 & 3 & 6 & 14 \\
\hline Group 20 & 2 & 1 & 1 & 4 \\
\hline Group 21 & 3 & 2 & 3 & 8 \\
\hline Group 22 & 5 & 2 & 7 & 14 \\
\hline Group 23 & 2 & 1 & 0 & 3 \\
\hline
\end{tabular}




\begin{tabular}{lllll}
\hline Group 24 & 3 & 2 & 6 & 11 \\
\hline
\end{tabular}

\section{Conclusion}

The result showed that engineering was able to use their creativity to come out with many methods of solving the real world problem. The real world problem with the components of fluency, flexibility and originality in creativity can be used to measure the creativity among the groups of students and this also aligned with assessment of creativity by Palaniappan (2012).

The assessment of creativity in this research was based on the use of scale as to compare the creativity level among the groups and this was in line with Treffinger and others (2002) as they used rating scale as an assessment in creativity.

The results of this research can also be used as a guideline in the future assessment of creativity among the groups.

\section{Acknowledgments}

The authors would like to express their appreciation for the support of the sponsors with grants QJ14H17 initiated by MOHE.

\section{References}

Ahern, A., O'Connor, T., McRuairc, G., McNamara, M., \& O’Donnell, D. (2012). Critical thinking in the university curriculum-the impact on engineering education. European Journal of Engineering Education, 37(2), 125-132. https://doi.org/10.1080/03043797.2012.666516

Barlow, C. M. (2000). Guilford's Structure of the Intellect.

Bath, D., Smith, C., Stein, S., \& Swann, R. (2004). Beyond mapping and embedding graduate attributes: bringing together quality assurance and action learning to create a validated and living curriculum. Higher Education Research and Development, 23(3), 313-328. https://doi.org/10.1080/0729436042000235427

Besemer, S. P. (1997). Creative Product Analysis: The Search for a Valid Model for Understanding Creativity in Products. University of Bergen, Department of Psychosocial Science.

Besemer, S. P., \& O'Quin, K. (1987). Creative product analysis: Testing a model by developing a judging instrument. Frontiers of creativity research: Beyond the basics, 367-389.

Besemer, S. P., \& O'Quin, K. (1993). Assessing creative products: Progress and potentials. Nurturing and developing creativity: The emergence of a discipline, 331-349.

Besemer, S. P., \& O'Quin, K. (1999). Confirming the three-factor creative product analysis matrix model in an American sample. Creativity Research Journal, 12(4), 287-296. https://doi.org/10.1207/s15326934crj1204_6

Besemer, S. P., \& Treffinger, D. J. (1981). Analysis of Creative Products: Review and Synthesis*. The Journal of Creative Behavior, 15(3), 158-178. https://doi.org/10.1002/j.2162-6057.1981.tb00287.x

Boden, M. A. (1998). Creativity and artificial intelligence. Artificial Intelligence, 103(1), 347-356. https://doi.org/10.1016/S0004-3702(98)00055-1

Chang, L. (Ed.). (2006). Wisdom for the soul: Five millennia of prescriptions for spiritual healing. Gnosophia Publishers.

Felder, R. M. (1987). On creating creative engineers. Engineering education, 77(4), 222-227.

Genco, N., Holtta-Otto, K., \& Seepersad, C. C. (2012, January). An experimental investigation of the innovation capabilities of undergraduate engineering students. Journal of Engineering Education, 101(1), 60-81 https://doi.org/10.1002/j.2168-9830.2012.tb00041.x

Guilford, J. P. (1967). The nature of human intelligence. New York: McGraw-Hill. https://doi.org/10.1007/BF00367914

Haylock, D. W. (1987). A framework for assessing mathematical creativity in school children. Education Studies in Mathematics, 18(1), 59-74.

Higgins, L. F. (1999), "Applying principles of creativity management to marketing research efforts in high-technology markets", Industrial Marketing Management, 28, 305-317. https://doi.org/10.1016/S0019-8501(98)00042-X 
Hilala, H. M. H., Husinb, W. N. I. W., \& Zayeda, T. M. (2013). Barriers to Creativity among Students of Selected Universities in Malaysia. International Journal of Applied, 3(6).

Isaksen, S. G. (1989). Creative problem solving: A process for creativity. Buffalo, NY: Center for Studies in Creativity

Isaksen, S. G., Dorval, K. B., \& Treffinger, D. J. (2011). Creative approaches to problem solving: A framework for change. Kendall Hunt Publishing Company.

Krutetskii, V. A. (1976). The psychology of mathematical abilities in school children. Chicago: University of Chicago Press.

Liu, Z., \& Schonwetter, D. J. (2004). Teaching creativity in engineering. International Journal of Engineering Education, 20(5), 801-808.

Newell, A., \& Shaw, J. C. (1972). The process of creative thinking. In A. Newell, \& H. A. Simon (Eds.), Human Problem Solving (pp. 144-174). Prentice Hall, Englewood Cliffs, NJ.

Osborn, A. F. (1942). How to think up.

Osborn, A. F. (1953). Applied imagination, principles and procedures of creative thinking.

Palaniappan, A. K. (2012). Web-based Creativity Assessment System. International Journal of Information and Education Technology, 2(3), 255. https://doi.org/10.7763/IJIET.2012.V2.123

Runco, M. A. (1993). Divergent thinking, creativity, and giftedness. Gifted Child Quarterly, 37(1), 16-22. https://doi.org/10.1177/001698629303700103

Runco, M. A. (1993a). Creativity as an educational objective for disadvantaged students (RBDM 9306). Storrs: University of Connecticut, The National Research Center on the Gifted and Talented.

Tong, L. F. (2003). Identifying essential learning skills in students' engineering education. Proceedings of HERDSA 2003.

Treffinger, D. J., Young, G. C., Selby, E. C., \& Shepardson, C. (2002). Assessing Creativity: A Guide for Educators. National Research Center on the Gifted and Talented.

Wallas, G. (1926). The art of thought.

Wilbur, R. (2013). Boxed In: The Lack of Creative Thinking in Engineering Students. Undergraduate Research Posters, 1.

\section{Copyrights}

Copyright for this article is retained by the author(s), with first publication rights granted to the journal.

This is an open-access article distributed under the terms and conditions of the Creative Commons Attribution license (http://creativecommons.org/licenses/by/4.0/). 